\title{
Prioritizing Barriers to Implementing More CDM Projects in Indonesia: An Application of AHP
}

\author{
Jun Ichihara $^{1} \&$ Toshihiro Uchida ${ }^{2}$ \\ ${ }^{1}$ Institute for Global Environmental Strategies (IGES), Japan \\ ${ }^{2}$ School of Economics, Chukyo University, Japan \\ Correspondence: Jun Ichihara, Institute for Global Environmental Strategies (IGES), 2108-11 Kamiyamaguchi, \\ Hayama, Kanagawa 240-0115, Japan. E-mail: ichihara@iges.or.jp
}

Received: July 8, 2014 Accepted: July 23, 2014 Online Published: August 22, 2014

doi:10.5539/ass.v10n18p191

URL: http://dx.doi.org/10.5539/ass.v10n18p191

\begin{abstract}
The issue of geographic equity has been one of the greatest concerns throughout the history of the CDM. To encourage wider implementation of the CDM or a reformed CDM and new market-based mechanisms in the future, it is necessary to identify the barriers that hinder implementation of CDM projects in underrepresented countries. This paper quantitatively analyzes the relative significance of barriers to implementing CDM projects in Indonesia. Using the analytic hierarchy process (AHP), the results revealed that the barriers related to financing, the carbon market, and international CDM policies and rules are the three major categories of barriers. Barriers that are primarily related to domestic factors, except financing barriers, turned out to be relatively less significant. Over the past several years, substantial resources have been devoted to capacity building activities. However, our results indicate that we should at least carefully reexamine how to distribute our resources among various barriers in the future.
\end{abstract}

Keywords: clean development mechanism, climate change, analytic hierarchy process, AHP, Indonesia

\section{Introduction}

The Clean Development Mechanism (CDM) is one of the three market mechanisms defined under the Kyoto Protocol. It is intended to offer low-cost options for greenhouse gas emission reduction by developed countries (Annex I countries) while contributing to sustainable development of the host countries (developing countries). From the viewpoint of enhancing sustainable development contributions, it is preferable that CDM projects are distributed across countries equitably so that many developing countries can reap the benefit of the CDM (Nicolas, Arens, \& Sterk, 2012). However, both the number of registered projects and the share of CERs (Certified Emission Reductions) have been disproportionately concentrated in a handful of countries, such as China, India and Brazil (Kirkman, Seres, Haites, \& Spalding-Fecher, 2012). The idea that CDM projects should be equitably distributed across countries is called the issue of "geographic equity", and it has been one of the greatest concerns throughout the history of the CDM (Kirkman et al., 2012). To encourage wider implementation of the CDM or a reformed CDM and new market-based mechanisms in underrepresented countries in the future, it is necessary to identify the barriers that hinder implementation of CDM projects in those countries. However, the previous studies tend to be limited to anecdotal evidence, and there is a paucity of academic studies, particularly academic studies that employ quantitative analyses.

Among the previous studies, Ellis and Kamel (2007) classified CDM implementation barriers in developing countries into the following four categories: (1) country-level barriers related to the CDM, (2) country-level barriers not specifically related to the CDM, (3) project-level barriers, and (4) international-level barriers. They then proposed policy prescriptions that would overcome these barriers. However, their classification and analysis is limited to anecdotal evidence, and they did not conduct detailed data analyses. Burian, Arens, Sterk, \& Wang-Helmreich (2011) focused on 11 least-developed countries in sub-Saharan Africa and analyzed barriers to implementing CDM projects. They collected each country's data on indicators grouped under five major categories including abatement potential, CDM promotion activities, institutional structures related to the CDM, general business conditions, and political preferences for sustainable development. They then compared each country's strengths and weaknesses based on these indicators. However, their study is limited in scope in that statistical analyses were not conducted beyond simply constructing the indicators. Furthermore, because they did 
not analyze the relative importance of the barriers, it remains unclear which barriers work as major obstacles to increasing CDM projects in these countries. There is another strand of research that applies econometric analysis to investigate the determinants of the number of CDM projects in each country (e.g., Flues, 2010). This type of study uses country-level macroeconomic variables such as per capita GDP and trade openness. However, it is difficult to improve these macroeconomic variables in a short period of time for the purpose of increasing CDM projects, and in this sense, the studies tend to have weak policy implications.

Against this background, this study employs analytic hierarchy process (AHP) to quantitatively analyze the relative significance of barriers that inhibit implementation of CDM projects. Specifically, we attempt to identify the CDM implementation barriers in Indonesia by conducting a questionnaire survey of Indonesian CDM stakeholders and applying AHP. We also conduct interviews with the same stakeholders to obtain their concrete experiences on the barriers. This complements the quantitative results of AHP and provides us with a more complete picture of the barriers.

Indonesia is one of the underrepresented countries. It has the 7th largest greenhouse gas emissions in the world and the 3rd largest emissions among developing countries in 2009 if emissions from land use, land-use change and forestry (LULUCF) are included (Note 1). Because Indonesia has a small number of CDM projects relative to its large mitigation potential (Ichihara, 2008), it is expected that the Indonesian CDM stakeholders have experienced some major barriers that inhibit implementation of CDM projects. At the same time, Indonesia had 144 registered CDM projects as of February 2014, and thus, the country has accumulated CDM experiences to some extent (Note 2). This combination makes Indonesia an appropriate country for our study because it is likely that the Indonesian CDM stakeholders can provide a good evaluation of the nature of the barriers based on their sufficient hands-on experiences.

The rest of the paper is organized as follows. The next section explains the current state of the CDM in Indonesia. Section 3 describes the research methods, and section 4 explains the results. Section 5 presents the paper's conclusions.

\section{The Current State of the CDM in Indonesia}

This section explains policy and institutional arrangements of the CDM and the current state of CDM projects in Indonesia.

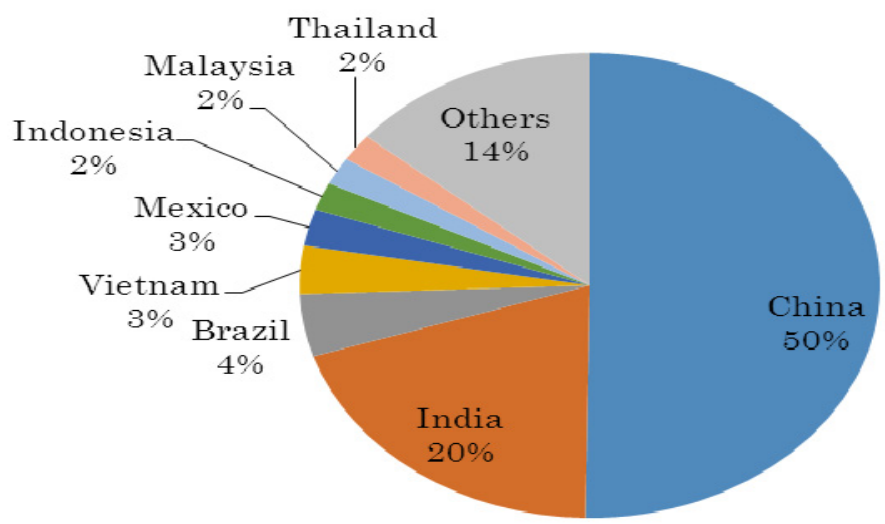

Figure 1. The number of registered CDM projects by country (source: IGES CDM project database (Note 3))

Indonesia signed the Kyoto Protocol in 1998 and ratified it in 2004. As part of the CDM implementation system of Indonesia, the National Committee on Clean Development Mechanism (Komisi Nasional Mekanisme Pembangunan Bersih) was established in the role of Designated National Authority (DNA) by the Ministerial Decree (by Ministry of Environment) No.206/2005. The National Committee consists of a secretariat, a technical team and an expert group. Regarding its function, the National Committee has the responsibility of deciding whether to approve proposed CDM projects. The National Committee also establishes rules for approval procedures and assessment criteria on sustainable development. The National Committee makes approval decisions using the technical team's evaluation if the proposed projects meet the sustainable development criteria in economic, social and environmental aspects. The Committee can also utilize inputs of experts as well as results of stakeholder forums. 
With reference to the current state of CDM projects in Indonesia, it cannot be said that Indonesia has successfully implemented CDM projects compared with its potential. As of February 2014, the number of CDM projects registered by the CDM Executive Board was 144 in Indonesia (IGES CDM project database). This accounts for as little as $2 \%$ of the world total (7448 projects) and is much smaller compared to China's $50 \%$ (registered 3742 projects) and India's 20\% (1477 projects) (See Figure 1). Similarly, the amount of CERs (Certified Emission Reductions) issued in Indonesia accounts for only $0.7 \%$ of the world total.

Regarding the potential of CDM projects in Indonesia, the National Strategy Studies by the Ministry of Environment, Indonesia, estimated that the potential share of Indonesia in the global CDM market will be $6 \%$ in all sectors combined, including LULUCF (Ministry of Environment, 2001; Ministry of Environment, 2003). Jakeman, Heyhoe, Pant, Woffenden, \& Fisher (2001) also estimated that Indonesia has the potential for having a share of $3.4 \%$ in the global CDM market and 38.6\% in the ASEAN from 2001 to 2015. However, the current status of implementation of CDM projects in Indonesia falls short of the above estimates. With a view to CDM project types, major project types currently implemented in Indonesia are biomass, renewable energy, methane recovery and utilization, and energy efficiency improvement. Indonesia has huge CDM potential in the forestry sector, but there are no forestry (afforestation and reforestation) projects registered in Indonesia despite 52 projects being registered in the world. In sum, it cannot be said that Indonesia has successfully implemented CDM projects so far.

Few previous studies have explored barriers to CDM implementation in Indonesia. Restutia and Michaelowa (2007) examined the economic potential of a bagasse cogeneration CDM project in Indonesia. They determined that the main barriers are technical challenges in the bagasse electricity-generation, technological uncertainties of efficient boilers, institutional and regulatory uncertainties related to the energy business, and other barriers associated with project developers, including managerial resource and organizational barriers. Ichihara (2008) showed by conducting interviews with key stakeholders in Indonesia that domestic regulatory factors such as the weak enforcement of regulations and related political uncertainties and difficulties in arranging project finance are the crucial factors for CDM project implementation. However, these studies are based on qualitative analyses, and thus, the present study aims to bridge the gap of the relevant previous studies by quantitatively analyzing the significance of barriers that hinder implementation of CDM projects.

\section{Methods}

The main analytical method used in this study is AHP. There are previous studies that employed AHP to examine barriers to implementation of specific types of technologies and projects. These include studies on energy efficiency in small-scale firms in India (Nagesha \& Balachandra 2006), cleaner production in small- and medium-sized enterprises (SMEs) in China (Shi, Peng, Liu, \& Zhong, 2008), cleaner technology in SMEs in China (Sizhen, Yan, Han, \& Ping, 2005), green supply chain management in India (Govindan, Kaliyan, Kannan, \& Haq, 2014), and cleaner generation technologies in small developing power systems in Sri Lanka (Wijayatunga, Siriwardena, Fernandoa, Shrestha, \& Attalage, 2006). In our study, we apply AHP based on a questionnaire survey of the CDM stakeholders in Indonesia and identify the relative significance of the CDM implementation barriers. In addition, we conduct interviews with the same stakeholders to obtain their concrete experiences and complement the quantitative results obtained by AHP.

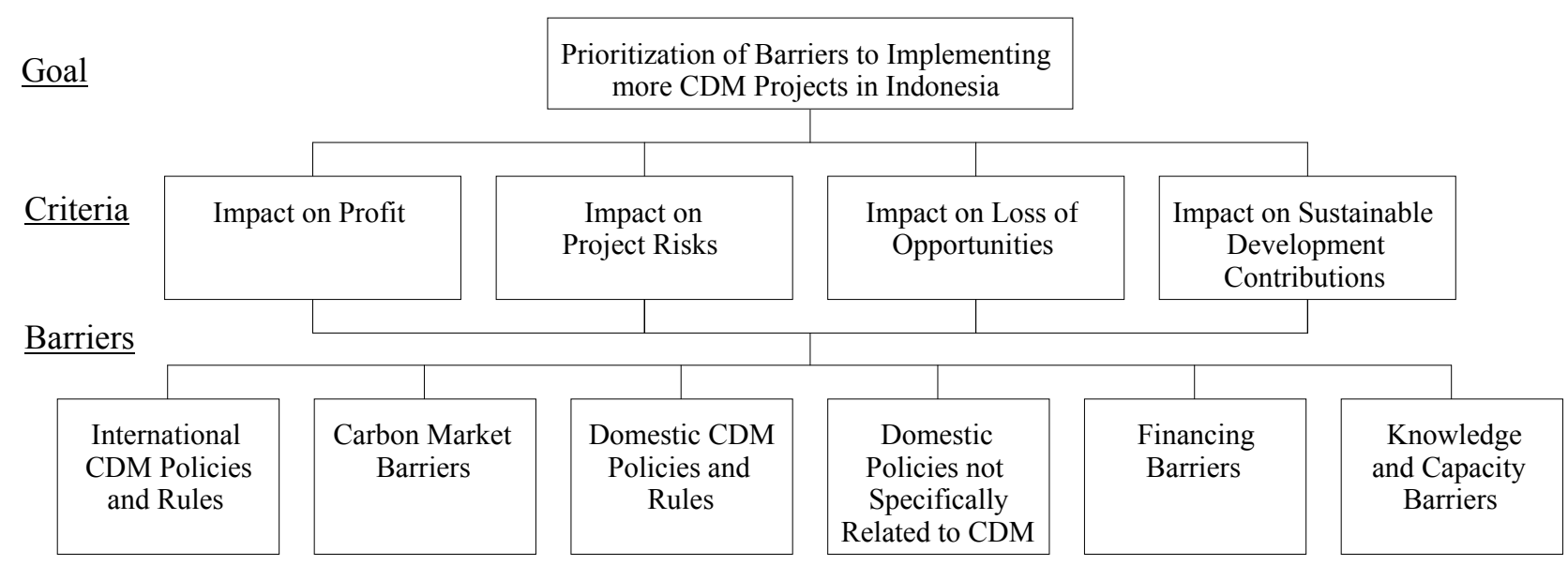

Figure 2. The hierarchy diagram of CDM implementation barriers 
The first step in applying AHP is to formulate a decision-making problem in a hierarchical structure. The hierarchy often takes a three-level form of a goal, criteria, and alternatives. The purpose of the decision-making problem is usually to evaluate the relative desirability of alternatives in achieving the goal. In this study, we formulate our decision-making problem in a slightly different way. The purpose of our decision-making problem is defined as evaluating the relative significance of barriers (the barriers for CDM implementation) rather than evaluating the relative desirability of alternatives. Accordingly, our hierarchy takes a form of goal-criteria-barriers rather than goal-criteria-alternatives. This formulation follows Nagesha and Balachandra (2006), which investigated the barriers that small-scale firms encounter in pursing energy efficiency and applied AHP to analyze the relative significance of the barriers. This study applies their analytical framework to the context of CDM implementation barriers.

By summarizing the above argument, a hierarchy diagram of the decision-making problem of this study is constructed as shown in Figure 2. The first level represents the goal of this problem, which is defined as "prioritization of barriers to implementing more CDM projects in Indonesia". That is, we would like to rank the relative significance of the CDM implementation barriers. The second level represents criteria. It shows what type of criteria the CDM stakeholders use when judging whether a certain category of barriers is significant. The third level represents the categories of barriers that hinder implementation of CDM projects.

In Figure 2, four criteria and six categories of barriers are already written concretely, but in general, factors in levels 2 and 3 (criteria and barriers in this case) must be appropriately determined through some research. Indeed, we constructed Figure 2 based on the literature review and interviews in the following manner. We first selected several candidates for criteria and barriers through the literature review (the literature includes Ellis \& Kamel, 2007; Ichihara, 2008; Burian et al., 2011; Nyaoro \& Chatterjee, 2011; CDM Policy Dialogue, 2012; Hwang, 2012). Then, we conducted 10 interviews in December 2012 with CDM stakeholders in Indonesia, including private sector project proponents, government officials, and consultants. In the interviews, we asked their opinions on major barriers for implementation of CDM in Indonesia and further collected concrete examples of barriers. In addition, we asked stakeholders' views on whether the criteria and the categories of barriers we selected were appropriate. Based on the interview results, we modified the criteria and the barriers, and they were grouped into the four criteria and six categories of barriers shown in Figure 2. The details of each of the criteria and barriers are as follows.

\section{Criterion 1: Impact on Profit}

This criterion measures how much profit is decreased due to the presence of barriers. Because the CDM is inherently a market activity, CDM stakeholders are likely to care about profit. Thus, the impact on profit is likely to be an important criterion in judging whether a certain factor is a barrier.

\section{Criterion 2: Impact on Project Risks}

This criterion measures how much project risks are increased due to the presence of barriers. Impact on profit is concerned with the expected level of profit, while impact on project risks is concerned with the spread of profit and other risks involved in the project. Because there are many risks in the CDM, this is likely to be one of the important criteria.

\section{Criterion 3: Impact on Loss of Opportunities}

Some CDM projects may not be implemented due to the presence of barriers. This indicates that opportunities for implementing CDM projects are lost due to the barriers. Impact on loss of opportunities measures the degree of loss of opportunities due to the presence of barriers.

\section{Criterion 4: Impact on Sustainable Development Contributions}

This criterion measures how much sustainable development contributions are decreased due to the presence of barriers. The Kyoto Protocol states that contributions to sustainable development are one of the major objectives of the CDM, and thus, the stakeholders may consider this an important criterion.

As part of deriving the relative significance of barriers by AHP, we also derive the relative importance of these criteria. Suppose the results of the AHP analysis indicate that Criterion 1 (Impact of Profit) is the most important among the four criteria. Then, this implies that the stakeholders attach the greatest importance to the impact on profit when judging which barriers are most significant. We next explain each category of barriers.

\section{1st category of barriers: International CDM Policies and Rules}

The barriers in this category are related to the CDM policies, rules, and their implementation at the international level. Various criticisms have been reported regarding the rules and procedures governed by the CDM Executive 
Board and performance of Designated Operational Entities (DOEs) in validation and verification processes (Nicolas et al., 2012; CDM Policy Dialogue, 2012). For example, CDM methodologies are sometimes insufficiently developed, and there are delays in deciding which project types are eligible (Ellis \& Kamel, 2007). In addition, although additionality of emission reductions from a project is a fundamental concept of the CDM, its application tends to be subjective and lacks robustness (Nyaoro \& Chatterjee, 2011). Based on the literature review and the interviews, a list of possible examples in this category can be summarized as follows:

- Complicated and changing regulations and rules of the CDM;

- Unclear definition and subjective and non-robust application of "additionality" of the CDM;

- Unclear decision-making criteria and lengthy processes of validation, registration and verification;

- Insufficiently developed CDM methodologies and delays in deciding which project types are eligible under the CDM;

- DOE capacity and availability are limited given the small number of DOEs compared to growing number of CDM projects;

- Various strict rules on LULUCF CDM projects make them unattractive investment options;

Note that these are possible examples of the barriers that are suggested by the literature and the interviewees. The stakeholders may not consider all of these to be significant.

\section{2nd category of barriers: Carbon Market Barriers}

The barriers related to carbon markets are included in this category. The price of CER has dropped significantly since 2011 and there is little sign of an upturn (CDM Policy Dialogue, 2012). The current low price is likely to be a major source of a barrier given that it directly affects expected revenue from CDM projects. The preference of carbon market participants can also be a barrier. Some investors require the volume of expected CERs to satisfy a certain minimum size to utilize economies of scale (Eni-Ibukunm, 2014). This makes it difficult for small-scale projects to be viable. A list of possible examples in this category is as follows:

- International CDM market and CER prices are not stable;

- Change in demand for credits due to uncertain future climate regimes and changes in EU's climate policies;

- Slack resources for contribution to sustainable development is limited due to current low carbon prices;

- Constraints on the choice of project types and size due to minimum project requirements;

3rd category of barriers: Domestic CDM Policies and Rules

The barriers in this category are related to CDM policies and rules at the domestic level. Designated National Authorities (DNAs), organizations assigned by the national governments, have important roles of approving proposed CDM projects and checking the sustainable development contributions of the proposed projects. However, the DNAs have been criticized for a frequent lack of clear guidelines in their decision making, partly due to inadequate staffing (Ellis \& Kamel, 2007). In addition, national policies toward the CDM, such as legal status and ownership of CERs, are not clearly instituted in some countries (Ellis \& Kamel, 2007; Burian, 2011). A list of possible examples in this category is as follows:

- Lack of clear rules of DNA approval/the legal status and ownership of CERs;

- Inadequate staffing and office equipment of DNA;

- Insufficient government-led promotional measures and support, including development of databases used for project design document (PDD) developments (e.g., grid emission factors);

- No reporting, monitoring and verifying of rules regarding sustainable development impacts by DNAs;

4th category of barriers: Domestic Policies not Specifically Related to CDM

The barriers in this category are associated with domestic political systems, policies, and their implementation not specifically related to the CDM. Stability and credibility of domestic political systems and certainty of policies and regulations with steady enforcement are great concerns for investors because CDM projects typically continue for several years before the issuance of CERs (Ellis \& Kamel, 2007; Ichihara 2008). Lack of coordination among various government agencies can also be a barrier because it may result in fragmented and inconsistent policies toward the CDM (Valenzuela, 2014). For example, inappropriate tax incentives, such as subsidies for fossil fuels, can reduce the attractiveness of investment in CDM projects (Ellis \& Kamel, 2007). Sometimes, foreign ownership of or participation in natural resources, land, and particular sectors is restricted. 
These policies discourage some types of relevant projects (Ellis \& Kamel, 2007). A list of possible examples in this category is as follows:

- Lack of policy coordination among government agencies, especially between the central and local governments due to local autonomy;

- Unclear statements in policies, regulations and rules;

- Non-strict enforcement of existing rules/regulations (e.g., license rules, regulations of power purchase agreements (PPAs));

- Incentives (taxes, subsidies and regulations) not being properly designed, and distortions being present, particularly in the energy-related market;

- Government restrictions on foreign ownership of natural resources, land, and firms;

\section{5th category of barriers: Financing Barriers}

The barriers in this category are related to financing for CDM projects. Some types of CDM projects such as renewable energy require large initial investment. In addition, various costs are required before the issuance of CERs, including costs of conducting initial feasibility study, developing project design documents, validation costs, registration fee, and verification costs. Thus, securing finance is often a source of constraint for project development and implementation (Ellis \& Kamel, 2007). Currently, many CDM projects are domestically financed (Kirkman et al., 2012), but our interviews revealed there are many barriers related to domestic financing. These include lack of understanding on the CDM scheme by domestic financing institutions, inflexible banking regulations, and lack of favorable considerations for projects with high sustainable development contributions. A list of possible examples in this category is as follows:

- Lack of understanding of the CDM scheme by domestic financing institutions;

- Financing from domestic financial institutions being difficult;

- Inflexible domestic banking regulations and rules;

- Insufficient incentives (e.g., low-interest loans) for projects with high sustainable development contributions;

- Insufficient government financing;

- Insufficient international financing for CDM projects;

\section{6th category of barriers: Knowledge and Capacity Barriers}

The barriers in this category are related to lack of sufficient knowledge and capacity of the CDM among policymakers and stakeholders. This category is primarily concerned with domestic knowledge and capacity barriers. As to policymakers, insufficient knowledge can lead to inappropriate intervention that inhibits healthy growth of the CDM in the country (Ellis \& Kamel, 2007). Insufficient capacity among stakeholders can result in inefficient market behaviors. For example, if knowledge and capacity for determining appropriate technologies are limited within the country, project proponents may need to employ an inferior technology or consult with foreign experts. Furthermore, lack of knowledge and capacity concerning sustainable development contributions of the CDM can result in more projects with smaller sustainable development contributions. A list of possible examples in this category is as follows:

- Insufficient knowledge of the CDM among policymakers and private sector stakeholders;

- Non-professional educational background of stakeholders;

- Inappropriate application of technologies to the local situation;

- Insufficient knowledge on sustainable development;

- Lack of standard methodologies to evaluate sustainable development impacts;

- Lack of networking among CDM-related business entities (to share technical knowledge and experiences).

After selecting the four criteria and the six categories of barriers that are explained above, we conducted a questionnaire survey of Indonesian CDM stakeholders from January to March 2013 to apply AHP. The AHP questionnaire was conducted based on the method of paired comparison. The method asked respondents to make pair-wise comparisons of the importance of the criteria and the significance of the barriers. A 1-9 scale was used in the pair-wise comparisons. In January 2013, we invited 16 participants to a focus group workshop. The participants answered the questionnaire and shared their experiences on CDM barriers with us and other participants. After the workshop, we further contacted other CDM experts individually and collected their 
responses with the help of local consultants from January to March 2013. In addition to the AHP survey, we simultaneously interviewed the CDM stakeholders to obtain their concrete experiences on the barriers. This complements the quantitative results of AHP and provides us with a more complete picture of the barriers.

The total sample size is 29 , of which 13 are government officials and 16 are private sector proponents and consultants. In Indonesia, government officials are allowed to work as consultants, and many of the government officials in our sample have consulting experience. Additionally, many of the private sector proponents have current or previous consulting experience. Therefore, we do not distinguish between government officials, private sector proponents and consultants in the ensuing analyses. Although the sample size may seem relatively small, we believe this does not cause bias in the AHP analyses for two reasons. First, the number of experts deeply involved in Indonesian CDM is small. Thus, the sample size of 29 means we have successfully included a significant number of CDM experts in Indonesia. Second, AHP does not depend on the large sample theory of statistics. It is very common to apply the method to small samples, and the sample size of our study is reasonably large as an application of AHP (for example, the sample size of Govindan et al. (2014) is 6).

\section{Results}

This section presents the analytical results of AHP and discusses the relative significance of the barriers to implementing CDM projects.

\subsection{Relative Importance of Criteria}

As part of deriving the relative significance of barriers, we also derive the relative importance of the criteria. The relative importance of the criteria indicates which criteria the CDM stakeholders place greater importance on when judging whether a certain category of barriers is significant. The results are shown in Figure 3 . The numbers represent the relative importance of each criterion out of $100 \%$.

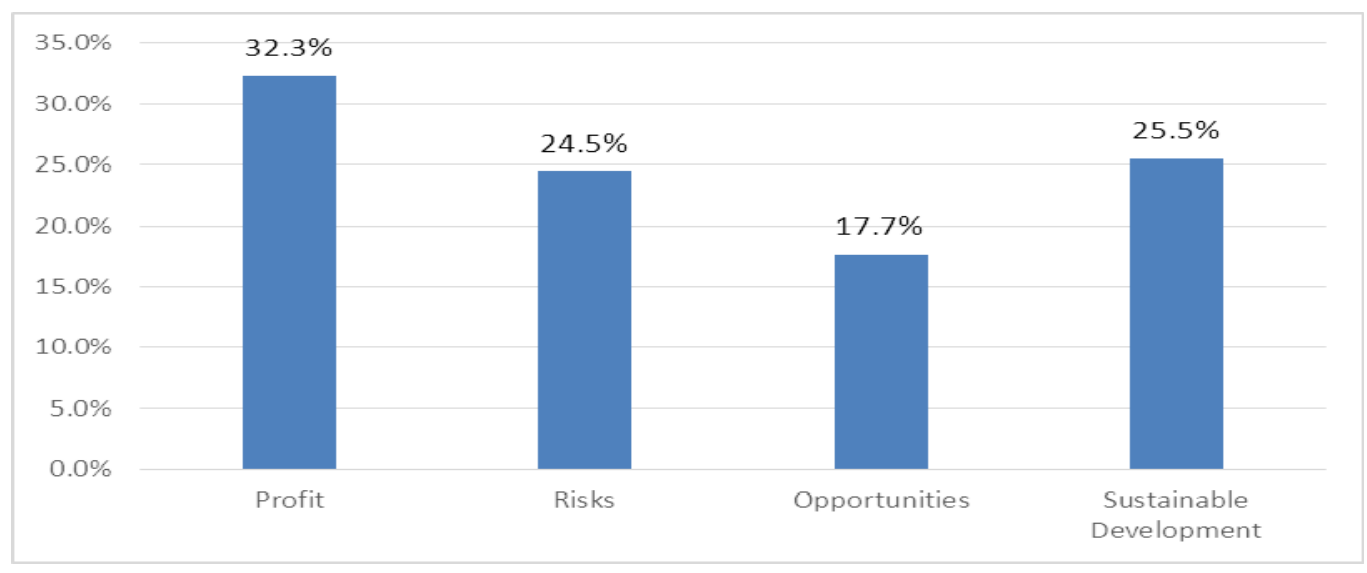

Figure 3. The relative importance of criteria

As observed, impact on profit has a relative importance of $32.3 \%$ and is regarded as the most important criterion. This is understandable given that the CDM is inherently a market activity. The second most important criterion is impact on sustainable development contributions, and the third most important is impact on project risks. They have almost the same level of relative importance. The least important is impact on loss of opportunities. However, it has a relative importance of $17.7 \%$, and this figure is not particularly low compared to other three criteria. The fact that sustainable development contributions turned out to be the second most important may seem a bit surprising. A reason for this could be the recent popularity of voluntary mechanisms such as the Gold Standard, which certify the quality of credits based on sustainable development contributions, and those credits tend to be sold at a higher price.

\subsection{Relative Significance of Barriers}

The main interest of this study is to derive the relative significance of barriers to implementing CDM projects. The results of AHP analysis are presented in Figure 4. The numbers represent the relative significance of each category of barriers out of $100 \%$. 


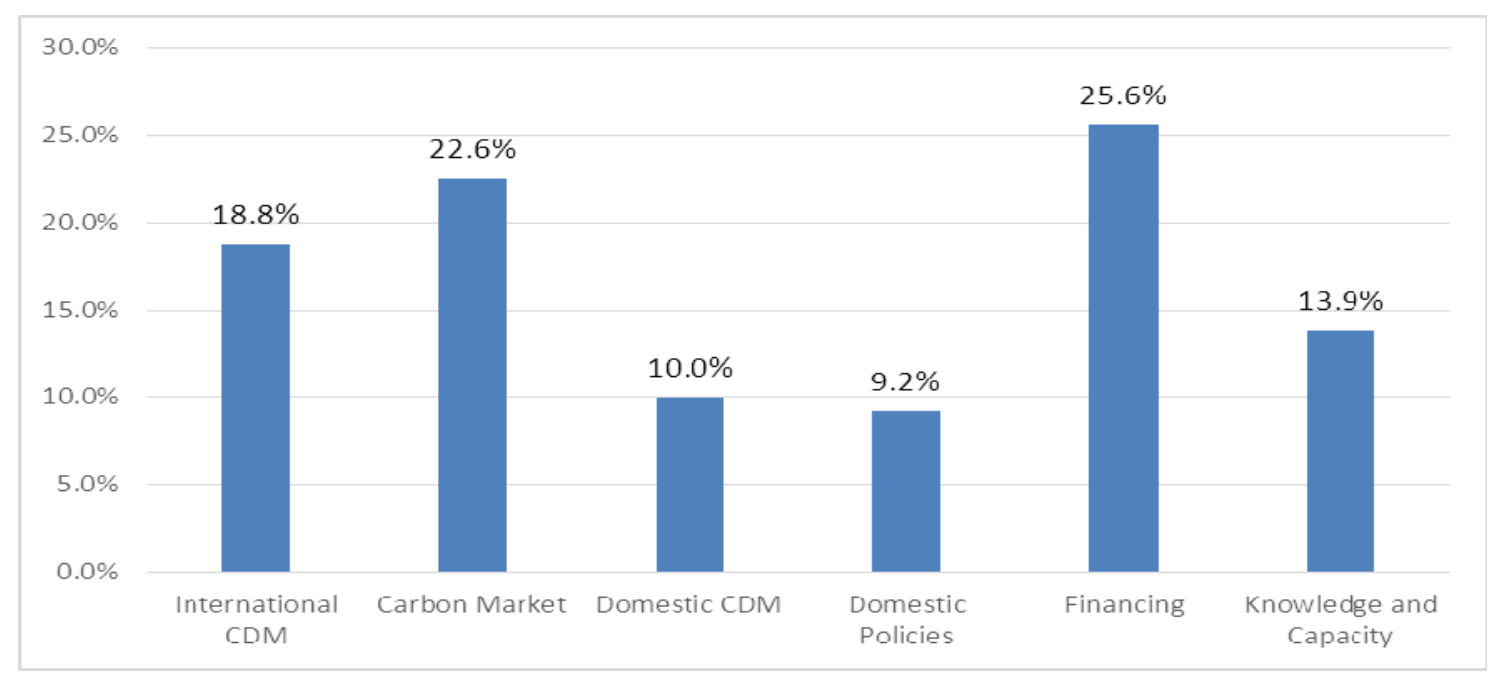

Figure 4. The relative significance of barriers

Financing barriers turned out to be the most significant category of barriers. Carbon market barriers are the second, and international CDM policies and rules are the third largest barriers. The remaining three categories of barriers - knowledge and capacity barriers, domestic CDM policies and rules, and domestic policies not specifically related to $\mathrm{CDM}$ - are all domestic barriers within Indonesia. Thus, except financing barriers, domestic factors turned out to be relatively less significant barriers.

As to financing barriers, our interview revealed that some project proponents have experienced difficulty in securing an investment loan from domestic financial institutions. Some of them complained that CERs from the project are not legally allowed as collateral, and this makes it very difficult to secure financing. However, an official of Bank Indonesia (the central bank of Indonesia) confirmed that CERs are legally allowed as collateral. The official ascribed the cause of financing barriers to inflexible internal rules on loans and risk-averse attitudes of domestic financial institutions. Our impression is that there is great confusion regarding financial regulations on the CDM among both lenders (financial institutions) and borrowers (project proponents), and this must be resolved to overcome financing barriers. Future studies need to examine possible countermeasures to address key issues within the financing barriers.

Compared to domestic barriers, the barriers that are mainly at the international level—carbon market barriers and international CDM policies and rules - were revealed to be major barriers. As to carbon market barriers, many stakeholders noted that the sluggish carbon prices are clearly a great concern and are major obstacles to implementing more CDM projects. They also added that even transaction costs for verification cannot be covered by CER revenue under the current low CER price. Ultimately, excess supply of carbon credits needs to be resolved through more stringent emission reduction targets by each country. If necessary, a price floor should be introduced to maintain carbon prices within a reasonable range (Kettner, Kletzan-Slamanig, Koppl, Schinko, \& Turk, 2011) so that revenue from CDM projects will become more predictable.

Regarding international CDM policies and rules, our interview revealed that there are various barriers in this category. For example, the stakeholders noted that (1) the CDM methodologies change too frequently, so the project design document (PDD) must keep updated during the preparation period for validation; (2) the processes for validation and verification are complex and lengthy partly due to the limited capacity of Designated Operational Entities (DOEs), which adds extra costs and leads to the loss of opportunities; and (3) the decision-making criteria by the CDM Executive Board (EB) are uncertain. It was noted that these problems are amplified because Indonesia does not have a local DOE. In addition to these barriers, there were opinions that the fact that Indonesia cannot adequately utilize the mitigation potential of its forest sector is a significant barrier. The CDM projects related to LULUCF are very difficult to implement due to the non-permanent types of CERs for afforestation and reforestation CDM projects (namely, temporary CERs and long-term CERs which are different from those of GHG emission reduction projects), and it makes them unattractive to buyers. Various obstacles in data collection, methodologies, and monitoring are other obstacles in this type of projects. Thus, under current international policies and rules, opportunities for utilizing the mitigation potential of the forest 
sector are lost.

\subsection{The Relative Significance of Barriers with Respect to Each Criterion}

To gain further insight, we broke down the relative significance of barriers with respect to each criterion. The results of AHP analysis are shown in Table 1. Each column represents the relative significance of barriers with respect to the criterion of the column. For example, the numbers in the column "impact on profit" indicate the relative significance of barriers when the only criterion of judgment is impact on profit. The numbers in each column add up to $100 \%$.

Table 1. The relative significance of barriers with respect to each criterion

\begin{tabular}{|c|c|c|c|c|}
\hline \multirow[b]{2}{*}{ Barriers } & \multicolumn{4}{|l|}{ Criteria } \\
\hline & $\begin{array}{l}\text { Impact on } \\
\text { Profit }\end{array}$ & $\begin{array}{l}\text { Impact on } \\
\text { Project Risks }\end{array}$ & $\begin{array}{l}\text { Impact on Loss of } \\
\text { Opportunities }\end{array}$ & $\begin{array}{l}\text { Impact on Sustainable } \\
\text { Development Contributions }\end{array}$ \\
\hline $\begin{array}{l}\text { International CDM Policies } \\
\text { and Rules }\end{array}$ & $14.9 \%$ & $19.8 \%$ & $28.9 \%$ & $15.8 \%$ \\
\hline Carbon Market Barriers & $28.6 \%$ & $21.7 \%$ & $21.4 \%$ & $16.5 \%$ \\
\hline $\begin{array}{lll}\text { Domestic } & \text { CDM } & \text { Policies } \\
\text { and Rules } & & \end{array}$ & $7.1 \%$ & $9.7 \%$ & $10.0 \%$ & $13.8 \%$ \\
\hline $\begin{array}{lrr}\text { Domestic } & \text { Policies } & \text { not } \\
\text { Specifically } & \text { Related } & \text { to } \\
\text { CDM } & & \end{array}$ & $6.7 \%$ & $9.8 \%$ & $8.4 \%$ & $12.3 \%$ \\
\hline Financing Barriers & $28.7 \%$ & $26.2 \%$ & $20.6 \%$ & $24.5 \%$ \\
\hline $\begin{array}{l}\text { Knowledge and Capacity } \\
\text { Barriers }\end{array}$ & $13.9 \%$ & $12.8 \%$ & $10.6 \%$ & $17.1 \%$ \\
\hline & $100.0 \%$ & $100.0 \%$ & $100.0 \%$ & $100.0 \%$ \\
\hline
\end{tabular}

There are several notable observations. First, with respect to impact on sustainable development contributions, financing barriers are much more significant than other categories of barriers. In the past, considerable international efforts have been made to appropriately evaluate carbon credits that have high sustainable development contributions and to reward them with premium prices. The establishment of the Gold Standard is a representative example. Because of these efforts, it now seems that larger barriers exist at the initial stages rather than at the final stages of CDM projects. To remove the barriers, more efforts should be targeted at financing. For example, low-interest loans can be introduced to provide economic incentives to the projects with high sustainable development contributions.

Second, with respect to impact on profit and impact on project risks, domestic barriers-domestic CDM policies and rules, domestic policies not specifically related to CDM, and knowledge and capacity barriers-are not significant compared to other barriers. Therefore, as long as the level and spread of profit are concerned, more efforts should be targeted at removing international barriers and financing barriers.

Third, with respect to impact on loss of opportunities, international CDM policies and rules are quite significant, while knowledge and capacity barriers are not. As we argued in the previous section, implementation of CDM projects in the LULUCF sector is quite difficult, and the opportunities for utilizing its huge mitigation potential are considered lost due to the current international policies and rules. Over the past several years, a vast amount of resources has been devoted to capacity-building activities (Okubo \& Michaelowa, 2010). Partly due to these activities, it is likely that the current level of knowledge and capacity is not recognized as a significant category of barriers that would lead to the loss of opportunities. Instead, in our interviews, many stakeholders mentioned that uncertainty, inflexibility and complications of the current international CDM policies are significant barriers. Therefore, we should at least carefully reexamine how to distribute our resources among various barriers in the future.

\section{Conclusions}

This paper analyzed the relative significance of barriers that inhibit implementation of CDM projects. Specifically, we applied AHP by conducting a questionnaire survey of Indonesian CDM stakeholders. The results 
revealed that financing barriers, carbon market barriers, and international CDM policies and rules are the three major categories of barriers. Barriers that are primarily related to domestic factors turned out to be relatively less significant.

Our results indicate that we should at least carefully reexamine how to distribute our resources among various barriers in the future. For example, a significant amount of resources has been devoted to capacity-building activities over the past several years (Okubo \& Michaelowa, 2010). However, likely due to these recent activities, our study revealed that knowledge and capacity barriers are not currently considered a significant category of barriers. Rather than trying to evenly enhance the knowledge and capacity of stakeholders, it would be more efficient to allocate relevant budgets for reforming more significant barriers such as international policies and rules, financing, and carbon market. Similarly, considerable international efforts have been made to provide economic incentives for carbon credits with high sustainable development contributions. However, it seems that larger barriers now exist at the initial stages rather than the final stages of CDM projects. In this case, more efforts can be targeted at securing financing for the projects with high sustainable development contributions.

This study focused on Indonesia, but the same analyses can be applied to other countries. Because AHP produces quantitative results that can be compared across countries, further insight can be obtained from comparative studies. Different countries have their own culture, development history, and economic and political institutions. These differences may lead to divergent outcomes in CDM implementation barriers, which may elucidate why certain factors are major barriers in some countries and not in other countries. This is a possible direction for future research.

\section{Acknowledgments}

Authors wish to acknowledge the Ministry of the Environment, Japan, for supporting this research. The authors are thankful to all respondents, interviewees and participants in focus group discussion for sharing concrete experiences on CDM barriers.

\section{References}

Burian, M., Arens, C., Sterk, W., \& Wang-Helmreich, H. (2011). Integrating Africa's least developed countries into the global carbon market: Analyzing CDM implementation barriers. Federal Ministry for the Environment, Nature Conservation and Nuclear Safety (BMU), Germany.

CDM Policy Dialogue. (2012). Climate Change, Carbon Markets and the CDM: A Call to Action. Report of the High-Level Panel on the CDM Policy Dialogue. Retrieved from http://www.cdmpolicydialogue.org/report/ rpt110912.pdf

Ellis, J., \& Kamel, S. (2007). Overcoming barriers to Clean Development Mechanism projects. Organization for Economic Co-operation and Development (OECD) and International Energy Agency (IEA).

Eni-Ibukunm, T. A. (2014). International Environmental Law and Distributive Justice. New York, NY: Routledge.

Flues, F. (2010). Who hosts the Clean Development Mechanism? Determinants of CDM project distribution. CIS Working Paper No.53, Center for Comparative and International Studies, ATH Zurich and University of Zurich.

Govindan, K., Kaliyan, M., Kannan, D., \& Haq, A. N. (2014). Barriers analysis for green supply chain management implementation in Indian industries using analytic hierarchy process. International Journal of Production Economics, 147(B), 555-568. http://dx.doi.org/10.1016/j.ijpe.2013.08.018

Hwang, J. (2012). Lengthy UN Auditing Procedures Threaten to Detail Climate Change Action. Strategic Review (The Indonesian Journal of Leadership, Policy and World Affairs), 80-88.

Ichihara, J. (2008). The Current Status and Barriers to the Implementation of CDM Projects in Indonesia (Indonesia ni okeru CDM projekuto jisshino genjo to kadai). Papers on Environmental Information Science (Kankyo Jouhou Kagaku Ronbunshu), 22, 85-90. (In Japanese).

Jakeman, G., Heyhoe, E., Pant, H., Woffenden, K., \& Fisher, B. S. (2001). The Kyoto Protocol, economic impacts under the terms of the Bonn agreement. ABARE Conference Paper 28, Canberra.

Kettner, C., Kletzan-Slamanig, D., Koppl, A., Schinko, T., \& Turk, A. (2011). Price volatility in carbon markets-Why it matters and how it can be managed. A working paper for the project ETCLIP "The challenge of the European carbon market-emission trading, carbon leakage and instruments to stabilize the $\mathrm{CO}_{2}$ price". Retrieved from http://angela.koeppl.wifo.ac.at/fileadmin/files/price_volatility_01.pdf 
Kirkman, G. A., Seres, S., Haites, E., \& Spalding-Fecher, R. (2012). Benefits of the Clean Development Mechanism 2012. United Nations Framework Convention on Climate Change.

Ministry of Environment. (2001). National Strategy Study on the Clean Development Mechanism in Indonesia. Ministry of Environment, Jakarta.

Ministry of Environment. (2003). National Strategy Study on CDM in Forestry Sector. Ministry of Environment, Jakarta.

Nagesha, N., \& Balachandra, P. (2006). Barriers to energy efficiency in small industry clusters: Multi-criteria-based prioritization using the analytic hierarchy process. Energy, 31, 1969-1983. $\mathrm{http} / / / \mathrm{dx}$.doi.org/10.1016/j.energy.2005.07.002

Nicolas, K., Arens, C., \& Sterk, W. (2012). The Clean Development Mechanism: The World's First Carbon Crediting Mechanism. Berlin: German Federal Ministry for the Environment, Nature Conservation and Nuclear Safety.

Nyaoro, J., \& Chaterjee, B. (2011). Governance of the Clean Development Mechanism (CDM). AEA Technology Briefing Paper ED56638. Retrieved from http://ec.europa.eu/clima/policies/ets/linking/docs/governance en.pdf

Okubo, Y., \& Michaelowa, A. (2010). Effectiveness of subsidies for the Clean Development Mechanism: Past experiences with capacity building in Africa and LDCs. Climate and Development, 2, 30-49. http://dx.doi. org $/ 10.3763 /$ cdev.2010.0032

Restutia, D., \& Michaelowa, A. (2007). The economic potential of bagasse cogeneration as CDM Projects in Indonesia. Energy Policy, 35(7), 3952-3966. http://dx.doi.org/10.1016/j.enpol.2007.01.014

Shi, H., Peng, S. Z., Liu, Y., \& Zhong, P. (2008). Barriers to the implementation of cleaner production in Chinese SMEs: Government, industry and expert stakeholders' perspectives. Journal of Cleaner Production, 16(7), 842-852. http://dx.doi.org/10.1016/j.jclepro.2007.05.002

Shishlov, I., \& Bellassen, V. (2012). 10 Lessons from 10 Years of the CDM. Climate Report No.37, CDC Climate Research. Retrieved from http://www.cdcclimat.com/IMG/pdf/12-10-05_climate_report_37_-_10_lessons _from_10_years_of_cdm.pdf

Sizhen, P., Yan, L., Han, S., \& Ping, Z. (2005). Studies on Barriers for Promotion of Clean Technology in SMEs of China. Chinese Journal of Population Resources and Environment, 3(1), 9-17. http://dx.doi.org/10.1080/ 10042857.2005.10677398

Valenzuela, J. M. (2014). Climate change agenda at subnational level in Mexico: Policy coordination or policy competition? Environmental Policy and Governance, 24(3), 188-203. http://dx.doi.org/10.1002/eet.1638

Wijayatunga, P. D. C., Siriwardena, K., Fernandoa, W. J. L. S., Shrestha, R. M., \& Attalage, R. A. (2006). Strategies to overcome barriers for cleaner generation technologies in small developing power systems: Sri Lanka case study. Energy Conversion and Management, 47(9-10), 1179-1191. http://dx.doi.org/10.1016/j. enconman.2005.07.003

\section{Notes}

Note 1. The Climate Analysis Indicators Tool (CAIT) 2.0, the World Resources Institute. Retrieved March 25, 2014, from http://cait2.wri.org

Note 2. IGES CDM project database. Retrieved March 29, 2014, from http://pub.iges.or.jp/modules/ envirolib/view.php?docid=967; http://pub.iges.or.jp/modules/envirolib/view.php?docid=1046

Note 3. IGES CDM project database. Retrieved March 29, 2014, from http://pub.iges.or.jp/modules/envirolib /view.php?docid=967; http://pub.iges.or.jp/modules/envirolib/view.php?docid=1046

\section{Copyrights}

Copyright for this article is retained by the author(s), with first publication rights granted to the journal.

This is an open-access article distributed under the terms and conditions of the Creative Commons Attribution license (http://creativecommons.org/licenses/by/3.0/). 